\title{
Abductionism: An attempt to achieve symbiosis
}

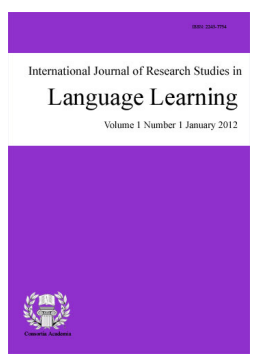

ISSN: $2243-7754$ Online ISSN: 2243-7762

Received: 01 October 2013

Revised: 21 November 2013

Accepted: 22 November 2013

OPEN ACCESS

\section{Abstract}

The logical problem of language acquisition has turned out to be a pivotal argument in favor of the nativist view on language acquisition. Although much work has been conducted in favor of inductionism and deductionism, the following paper is an attempt to cast lights upon the notion of abductionism in language acquisition in order to achieve symbiosis between deduction/induction and abduction. Though linguistic, much of Chomsky's writings are the revisited reflection on the philosophy pioneered by Plato and Peirce. Chomsky inclination towards Peirce's abductionism reflects the fact that Chomsky never ignores the role of input offered by the external world, although to him the role of things that are external to organism is looked from an inferior light. In sum, what the present paper tries to account that the genesis of any logic in language acquisition is best described as an integrative development of observational verification, theoretical falsification, and hypothetical explanation. Henceforth, looking at one's own scientific method (i.e., induction, deduction, and abduction) from a superior light entails ignoring the dynamicity of language acquisition.

Keywords: abduction; deduction; induction; input; poverty of stimulus; universal grammar 


\section{Abductionism: An attempt to achieve symbiosis}

\section{Introduction}

Much of the debate in language acquisition has attempted to revitalize Plato's Problem; that is, how language is acquired. Peirce (1998) referring to three modes of scientific methods - abduction, deduction, and induction - asserts that abduction refers to the process of making guesses as to the hypotheses, while deduction relies on the process of deriving results from the hypotheses raised, and induction on testing the hypotheses in order to derive consequences. Undeniably, according to Haig (2005), inductive approaches to scientific research, though addresses an essential part of logic of science, is not enough. The logical problem of language acquisition raises with the issue that language acquisition per se cannot be totally inductive. What makes nativists (e.g., Chomsky, 1965) incompatible with induction-based view of language acquisition is that an infinite number of hypothetical languages is inconsistent with the finite input sample. Furthermore, the nature of input that the child is exposed to is also both qualitatively and quantitatively defective so that one cannot rely on it to claim that children acquire merely language through input. Thus, how one comes from a finite set of rules to an infinite number of sentences and how it is possible that the child acquires language, although the input is defective, are among several questions that lead scholars (e.g., Chomsky, 1957) to take an abductive approach. In a nutshell, Chomsky likens language learning to Peirce's (1988) abductive reasoning; in fact, language acquisition is partly inborn and partly based on insight guessing.

In revitalizing Plato's problem, Chomsky (1957) arrives at this conclusion that human beings are equipped with an innate knowledge. Chomsky, underestimating inductionism, claims that environment cannot provide sufficient input for language acquisition. He refers to this limited environmental stimulus as poverty of stimulus. In effect, to nativists, claiming that a child can acquire language effortlessly and quickly is implausible. Children are endowed with an innate language faculty that guides them. The argument known as logical problem of language acquisition is based on the thesis that although children are exposed to degenerate input, they make their own mental representation of language that goes beyond the available input. Nevertheless, the present paper looking at the logical problem of language acquisition, claims that taking an absolute inclination toward either deduction, induction, or even abduction never paves the way towards a comprehensive solution to the logical problem of language acquisition. Henceforth, making an endeavor to achieve symbiosis between scientific methods, the paper, though centering upon the logic of abductionism, does not intent to stick the ideas of inductionism and deductionism to the margin but holds that it is time that scholars should make an endeavor to achieve symbiosis between three methods of logic, i.e., deductionism, inductionsim, and abductionism.

\section{Literature review}

Based on deduction-based view of language acquisition, children learn their first languages through hypothesis formulation and refutation. In this regard, Popper (1976) claims that growth of knowledge results from the procedure of trial and error. To Popper, falsifiability is a key feature of logic of science. If a theory is not falsifiable, it is not scientific. However, that something is falsifiable does not mean it is false; rather, it means that if it is false, then observation or experiment will at some point demonstrate its falsehood. For example, the statement that "all balls are round" is falsifiable because it is logically possible that a ball can be found in a different shape. Popper criticizes inductionism and logical positivism. To him, induction has no place in the logic of science. In fact, what makes the deductive method distinct from the inductive method is the fact that the former relies upon reasoning; henceforth, there is no doubt that deductive methods also cannot deal with all types of reasoning because it only relies upon premises which are known as certainly true. Thus, if a premise is not known a priori, then the process of deduction will be addressed in an inferior light.

Induction is not an excuse for "only seeing what you want to see" (Gibson, 1992, p. 238). Unlike 
Abductionism: An attempt to achieve symbiosis

deductionists, inductionists are compatible with verification rather than falsification, since unlike what Popper (1976) insists that falsification is the linchpin of logic of science, "it must be admitted that "propositions are not always postulated in the form of readily testable hypotheses" (Gibson, 1992, p. 16). In this regard, Hume (1977), unlike Popper, claims that inductive argument is not grounded in reason; in other words, it cannot be accounted for by reference to human beings' inferential faculty. In a sense, an inductive argument centers upon observation in order to arrive at a conclusion concerning something unobserved that may reveal in a form of prediction, generalization, and so forth (Lange, 2008).

In a sense, according to Hume (1977), we are not entitled to any degree of confidence to conclude a premise based on what has not been observed (cited in Lange, 2008). Gibson (1992) goes on to hold that to inductionists, data is made sense by studying it in vivo. In fact, "hypotheses are generated and expected to emerge throughout the course of the inquiry, rather than to magically appear at the outset" (p. 16). Nevertheless, like the deductive method, inductive method, though not grounded in reason, cannot investigate all reasoning because, to an inductivist, human beings come into the world with tabula rasa. In fact, nothing exists in the mind in order to help human beings to judge anything a priori. Still, as Lange (2008) puts forth, although "many philosophers have been in attempt to find a way around Hume's argument-to show that science and common-sense are justified in making predictions inductively. Despite these massive efforts, no response to date has received widespread acceptance" (p. 44).

To achieve symbiosis, Hanson (1958) contends that neither induction nor deduction constitutes the fundamental logic of science. Hanson indeed does not eliminate deduction and induction from the logic of science. Hanson contends that the logic of scientific activity is abduction by nature. Chomsky's (1957) ideas, although compatible with deductionism, is more influenced by Peirce's abductionism. As Agassi (1997) claims, "in linguistics no one has done more in this direction that Noam Chomsky, who criticized [inductionism]" (137). Still, inductionism is not legitimate to be stuck to the margin. As Agassi puts forth, "salvation will come from the increase, not the reduction, of the number of data to examine before fruitful examination can begin"(p. 138). Chomsky (1957) never denies the role of environment; he never claims that inductionism needs to be totally ignored in the interpretation of language acquisition. Nevertheless, he constantly "advertises ...his own ideas in a superior light ...but... his opponents' ideas in an inferior light” (Agassi, 1997, p. 143).

Put differently, claiming that both nurture and nature get involved in the process of language acquisition, the present writers inspired by Khun's (1970) incommensurability thesis, i.e., theories are incomparable, hold that methods of science; i.e., deductionism, inductionism, and abductionism should be looked from complementary perspectives rather than oppositional ones. Unlike Long (1993) who asserts where oppositions exist culling is necessary, based on Ellis's (1994) epistemic relativist view, all standards in theories are on a par that none of them is more defensible than the next. In fact, a society with several traditions is more successful than a monistic society. In fact, a pluralistic society provides us with the freedom of choice; the maturity of individuals in a society will be predicted if they are allowed to have a private interpretation of ideality. However, to a monistic society, there is only one correct standard that individuals are to pursue it since multiple theories are respected problematic (Long, 1993). Along the same line, defending deductionism, for instance, from a an absolute sense might connote that even if one does not have any prior knowledge of the case, he/she can get to the results. However, reality is something else. The paper goes on to defend that if the premises are not known to individuals, no results will be achieved; thus, deductionim, in this case, has probably no place in the logic of science. Henceforth, the paper finding the issue significant to pave the way towards a symbiotic availability of the three: deductionsim, inductionism, and abductionsim, assert there is no need to sift out the weaker methods.

\subsection{On the notion of abductionism}

The concept of abduction borrowed from the American philosopher Charles S. Peirce was introduced into linguistics by Henning Anderson (1973, cited in Deutscher, 2002). Chomsky was among the first who discussed abduction in line with innateness. However, Peirce's interpretation of abduction was later modified in his later 
writings. As Deutscher (2002) puts forth, earlier in the $19^{\text {th }}$ century, Peirce referred to induction, deduction, and abduction as three different modes of inference which were elaborated within the "straitjacket of Aristotelian Logic" (p. 471), but in the $20^{\text {th }}$ century, he rejected his earlier attempt to describe these three types ampliative inferences as permutations of Aristotelian syllogism; in this regard, he made an endeavor to crystallize contrast between abduction and deduction/induction. Moreover, in Peirce's later writings, different terms are used for abduction, including hypothesis and retroduction. To Peirce (1998), abduction refers to any form of explanatory hypotheses, while deduction and induction are simply "phases of testing an already hypothesis" (Deutscher, 2002, p. 471). Chomsky (1997, cited in Wilkin, 1999) also defines abduction as "a process in which the mind forms hypothesis according to some rules and selects among them with reference to evidence, and presumably, other factors" (p. 188).

Abduction, per se, involves inferencing a case from a rule and result. Abduction inference is based on the reasoner's guessing insight. On distinguishing the difference between induction and abduction, Deutscher (2002) writes that induction refers to "the generalization of a property from a sample to the whole class, [while] abduction ...is the conceptual leap from data to an explaining hypothesis” (p. 471). Deutscher also referring to Peirce states:

The great difference between generalization induction and hypothesis [abduction] is that the former infers the existence of phenomena such as we have observed in cases which similar, while hypothesis [abduction] supposes something of a different kind from what we have directly observed, and frequently something which it would be impossible for us to observe directly. (p. 471)

To draw a further distinction between induction and abduction, Deutscher (2002) gives an example. He asserts that seeing a few apples fall to the ground, one can infer by generalization that all apples will do so. This is induction, according to Peirce, is not enough to describe many of the inferences made in science. From the above example, one can also infer that all bodies proportional to their mass are attracted to the earth. This is a conceptual leap known as abduction. Berthele (2011), also, on elucidating the distinction between abduction and induction contends that abduction presupposes the knowledge of rules, whereas induction is about finding the rule based on a corpus of data.

In addition, what makes abduction, as a process of adopting explanatory hypotheses, distinct from induction is that abduction covers two operations, i.e., the selection and formation of plausible hypotheses (Wirth, 1998). Peirce (1998) inspired by Darwinian model of evolution, holds that selection is partly inborn and partly guessing instinct; evolution is not mechanical and material. Accordingly, Sørensen, Thellefsen, and Brier (2012) see human beings as part of a greater semeiotic mind in which we establish our own self through the experiences with the world.

In effect, Chomsky, likening language acquisition to abductive reasoning, turns out to be compatible with the undeniable role of external world on language acquisition. As to Sørensen, Thellefsen, and Brier (2012), Peirce's abductionism insists that human beings have no power of introspection, but all knowledge of the internal world is derived by hypothetical reasoning from our knowledge of the external world. This hypothetical reasoning is nothing but guessing. As to Peirce (1958, cited in Wirth,1998), in order to make fair guesses, abductive inference links the reasoner's guessing instinct with the principle of economy/parsimony, which is the leading consideration in abduction. Wirth asserts that the principle of economy, according to Peirce, refers to providing the possibility to prove a hypothesis with minimal effort and with maximal effect.

In a nutshell, Peirce's abductive reasoning is in fact influenced by the idea developed by William of Ockham known as Okham's Razor. Okham's Razor, as a principle of parsimony/economy, is widely used in the logic of science. The hidden feature of parsimony is the notion of simplicity. Simplicity in the field of logic of science contributes to problem solving issue. Accordingly, as to Peirce (1958, cited in Wirth, 1998), simplicity is the one that instinct suggests, that must be preferred. 
Abductionism: An attempt to achieve symbiosis

Nevertheless, the term simplicity can be ambiguous. According to Baker (2006), simplicity can be investigated from syntactic as well as ontological dimensions. To Baker, syntactic simplicity "roughly, [refers to] the number and complexity of hypotheses, and ontological simplicity [to] the number and complexity of things postulated" (p. 194). Baker continues that these two facets of simplicity generally refer to elegance and parsimony. Nevertheless, "Occam's Razor is frequently stated in a way which is ambiguous between the two notions [of syntactic and ontological]"(p. 194). In an Occam's Razor's principle, for instance, we have "Don't multiply postulations beyond necessity" (p. 194); to Baker, the term postulation is ambiguous as we do not know whether postulation refers to the entities being postulated, or the hypotheses doing the postulating, or both.

Chomsky (1957) appears to be in favor of ontological simplicity rather than syntactic simplicity. In this regard, Chomsky claims "the principles that embody our knowledge of language are by no means the simplest or most natural" (Laurence \& Margolis, 2001, p. 221). Henceforth, far from clinging to syntactic simplicity for the purpose of the present paper, it can be stated that the principles governing the language are not syntactically simple. To form a yes/no question, for instance, one cannot simply move the first 'is' to the front of the sentence:

That man who is in the class is my teacher.

*Is that man who in the class is my teacher?

Thus, there are some constraints on the movement of auxiliary. The reason why the second sentence is ungrammatical is because the auxiliary moved is not from the main clause. Henceforth, compatible with abductionism, we can claim that the two verbs (i.e., is) in the above sentence are semantically and lexically similar; thus, if learners are not familiar with the syntactic function of them, they will certainly confuse them. In this regard, it can be claimed that learners are equipped with the principles governing the syntactic knowledge of language. Furthermore, if one cannot draw a distinction the between the verb 'is' in the main clause with the verb 'is' in the subordinate clause, he/she will be susceptible to make a large number of errors. But, this picture of error correction has little basis in reality, and yet children do not make error of this sort.

\subsection{In disfavor with inductionism}

Hornstein and Lightfoot (1981) point out that the input the child is exposed to is deficient in three different respects: (1) the input is degenerated, (2) the input is insufficient, and (3) no negative evidence is supplied. Accordingly, Laurea (1995) also referring to the deficiency of input outlines three reasons concerning the deficiency of the input: Firstly, the language children hear is not always made up of grammatical sentences, but also slips of the tongue, false starts, and grammatical errors. Secondly, the set of sentences the child is able to handle is enormous in comparison with the limited set of sentences he/she actually hears. In the same line, Chomsky (1981) insists, "it is a near certainty that fundamental properties of the attained grammars are rapidly undetermined by evidence available to the language learner and must therefore be attributed to UG itself" ( $\mathrm{p}$. 38). Finally, as Chomsky goes on to hold, "children do not get explicit correction for the mistakes they make" (p. 111). In this regard, incompatible with the stream of inductionism, Chomsky $(1965,1981)$ maintains that there are three types of evidence available to children: (1) direct positive evidence, (2) indirect negative evidence, and (3) direct negative evidence.

Direct positive evidence is regarded the most relevant in language acquisition. Indirect negative evidence is in fact provided by UG which independently prevents certain syntactic configurations and syntactic phenomena from arising in the language; the same is true of morphological and phonological rules (Laurea, 1995). This connotes that the child is waiting to be reinforced about some kind of structure. In direct negative evidence, correction is done by parents when a child makes mistakes; however, this type of correction is not based on grammaticality judgment but on the basis of truth judgments (Laurea, 1995). Grammaticality judgment is concerned "with the relevance of Universal Grammar $(U G)$ to second language acquisition" (Schachter \& Yip, 1990, p. 381). Grammaticality judgment, further, argues that "if L2 learners are able to judge correctly ungrammatical sentences ruled out by universal constraints just on the basis of positive evidence from the target 
language, then they have access to UG" (Schachter \& Yip, 1990, p. 381). Truth judgment, in contrast, "bears no meaning on the learning of a language" (Laurea, 1995, p. 44). Henceforth, "children are ordinarily not corrected for whatever grammatical mistakes they make, so when they do make a mistake they do not know that they are wrong or how they are wrong" (Bloom, 1991, cited in Laurea, 1995, pp. 44-45). Although no one denies that some zealous parents correct their children, this is not the general basis of language acquisition.

Cook (1988) adds another type of evidence, which he calls the explanatory evidence that involves the explanation of grammatical rules. However, according to Laurea (1995), this type of evidence entails "a certain cognitive maturity and can be considered a kind of negative evidence, obviously not available to very young children" (p. 47).

There is no consensus regarding what types of evidence have a pivotal role in language acquisition. Those who subscribe to a nativist approach to language acquisition hold that positive evidence is all that is required for language acquisition to occur (Chomsky, 1965). However, those who are in favor of interactionist perspective see both positive and negative evidence as sufficient (Jabbari \& Niroomizadeh, 2005). What makes these types of evidence distinct is that negative evidence provides information to learners about what is not possible in the target language (Long, 1996). By the same token, Jabbari and Niroomizadeh (2005) assert, "negative evidence consists of information about the impossibility and ungrammaticality of a form or an utterance" (p. 47), while positive evidence refers to what might occur as authentic input in naturalistic conversations (Chaudron, 1988). Moreover, "positive evidence can function entirely by itself" (Jabbari \& Niroomizadeh, 2005, p. 47). However, Chomsky (1981) holds the idea that direct negative evidence is not necessary for language acquisition.

Honestly, Chomsky "has never suggested in any way that his work might be of benefit to L2 teaching" (Bourke, 2005, p. 85). Nevertheless, several scholars incompatible with some Chomskian ideology have conducted studies and put forth that indirect negative evidence may be relevant; Jabbari and Niroomizadeh (2005), in this regard, carried out a study where learners were asked to read a text provided with some kind of meaning-focused activity that incidentally assisted them to focus their attention to the target feature. In disfavor with Chomsky's claim on the inessentiality of direct negative evidence, Jabbari and Niroomizadeh, referring to Cook and Newson (1996), report that negative evidence such as explanations, explicit grammar teachings, and corrections of wrong sequences or ungrammatical sentences show what may not be done. In fact, to them, due to the unlearnability of some sentences form the positive evidence available, it is necessary to appeal to direct negative evidence.

Nevertheless, Laurea (1995), also, disfavoring negative evidence that children might be exposed to, holds that children hardly get corrected by their parents, so they receive no correction. This implies that the children must have a rich system of knowledge that predisposes them to acquire language. In effect, children's knowledge is tacit; that is, they cannot articulate grammar rules. To better appreciate the notion of evidence that children are supposed to be exposed to, the following part is specifically limited to this argument.

\subsection{Poverty of stimulus: In reaction to inductionism}

The poverty of stimulus argument holds that children are not exposed to enough evidence in order to infer the principles that govern language acquisition including structure dependency. Chomsky (1965) claims language learners make grammatical generalizations that do not appear in the input. These generalizations can be explained by appealing to what the innatists refer to as the poverty of the stimulus. The poverty of stimulus argument claims that the child should not be exposed to the input to rule out the hypotheses. The majority of innatists claim that children are equipped with a mechanism (i.e., LAD) that predisposes them to acquire language. To innatists, the so-called LAD is like an organ that grows. Such modular perspective towards language acquisition holds that mind is compartmentalized in different section and language has a location in the mind which is called language faculty. From the lens of an innatist, learning happens through internalization. To Laurence and Margolis (2001), knowledge is biologically programmed. Furthermore, the child has an intuition to 
Abductionism: An attempt to achieve symbiosis

judge the grammaticality of the sentences. Thus, according to Chomsky (1965), it is not necessary to tell the child which sentences are possible or not.

Poverty of stimulus, as one aspect of the logical problem, holds that the language input of a child is not sufficient to be able to conclude to the target language. What makes the induction task extremely difficult is that, in principle, infinite number of hypothetical languages is inconsistent with the finite input sample. Henceforth, relying on inductive method involves an infinite number of generalizations consistent with any finite sample of data. In this regard, Pinker (2004) asserts that any learner who correctly induces a function, theory, or grammar must respect prior ('innate') constraints on its hypothesis space; thus, the data alone are insufficient.

However, several philosophers (e.g., Goodman (1967); Putman, (1967) hold that poverty of stimulus argument "is incoherent, unsubstantiated, and rooted in misconceptions about the nature of language and language acquisition" (Laurence \& Margolis, 2001, p. 218). Goodman (1967) refers to Chomsky's claims as "unsubstantiated conjectures that cry for explanation by implausible and untestable hypotheses" (p. 75). Putman (1967) also asserts "Chomsky's thesis is essentially and irreparably vague" (p. 108). However, to several scholars (e.g., Laurence \& Margolis, 2001), "they [Goodman, 1967; Putman, 1967] go wrong” (p. 239). There is not much space to deal with why the scholars, Goodman and Putman, react towards Chomsky's nativist model except to claim that Chomsky's model is untestable if we are supposed to test his theory based on natural languages. However, it is worth mentioning that in disfavor with Goodman who suggests that to test Chomsky's theory, it is necessary to construct unnatural languages, the present writers are compatible with Laurence and Margolis (2001) who claim that if we appeal to unnatural languages, we implicitly understate Chomsky's nativism.

\subsection{Second language acquisition and abductionism}

Jovanovic and Krneta (2012) making a distinction between three modes of scientific method write that when a learner faces a new linguistic unit, he or she begins to make hypotheses about its meaning and its possible functions. Deductively, the student draws conclusion from hypotheses regarding the possible context the unit is to be used. And through the exposure to different exemplars in which the new unit is presented, the learner reinforces, modifies or refutes the initial hypothesis, and abductively, the learner begins to make a guess based on his/her overall linguistic knowledge. Jovanovic and Krneta further assert that L2 learners already have linguistic knowledge; henceforth, this potentiality will provide an advantage for learners in the related context to make use of this potential. In brief, the background knowledge including the world knowledge and linguistic knowledge, is conducive to the process of abduction. In this regard, Berthele (2011) contends abduction is conducive to the explanation "as to why bi-/multilinguals do better at the particular tasks...and, as a consequence of this first conclusion, why many bi-/multilinguals might be better at language learning in general" (p. 192).

It can be claimed that even the availability of a language system a priori in bi-/multilinguals do facilitate the process of abduction. Appealing to the Chaos/Complexity theory will also help us better appreciate the notion of abduction in adults. It is assumed that out of chaos emerges a new language which is a product of all the elements involved in the process, and which can be placed in a cline which has first and second languages as two opposing poles. The first language is considered as the initial condition for language learning (Larsen-Freeman, 1997). This initial condition will certainly be conducive to the process of second language learning. The first and second languages work as attractors. An attractor is "a region of a system into which the system tends to move" (Larsen-Freeman, 1997). The learner is first attracted to native language, and then to second language, and in his/her attempt to acquire the new language, he/she is attracted or repelled by one of the poles, and out of this cycle of attraction and repelling emerges interlanguage. Interlanguage works as a strange attractor, highly sensitive to its initial conditions. To Larsen Freeman, interlanguage is an open system and moves to the strange attractor which gives it both impetus and order. Indeed, fossilization occurs when interlanguage becomes close to a fixed-point attractor. Fossilization, according to Laurea (1995), may affect specific aspects of second language 
development, including phonology, morphology, and syntax. Henceforth, the learner is in an attempt to detect and gather information from the first language to contribute to the second language learning. Thus, the learner is similar to an abductive researcher. In fact, as to Shank (1993), the abductive researchers in the era of chaos/complexity are viewed as less like experimenter and more like a detective, a hunter-gatherer learning to gather information, to combine that information in search of new exciting venues of insights, and to turn to the world of experience directly for guidance.

\section{Conclusion}

There is not a consensus among scholars regarding the absolute basis of logical problem of language acquisition. To several scholars (e.g., Hume, 1977; Skinner, 1957), language acquisition is induction-based, while to others (e.g., Popper, 1976), it is quite deduction-based, and in linguistics, Chomsky (1957) inspired by Peirce is compatible with abduction. In brief, abduction allows us to reason from the experience at hand rather than by the data available or by hypotheses testing. Along the same line, Chomsky (1965), in disfavor with inductionism, claims that "knowledge of grammatical structure cannot arise by application of step-by-step inductive operation" (p. 57). Nevertheless, to Birjandi, Shakouri, and Mellati (2012), "no one is fair to take an absolutist perspective in denying the fact that what behaviorists... [did] in the past paved the way and provided an empirical tool for abductionists" (p. 1010) in order to claim that "relying on external input cannot account for the creative aspect of language use" (p. 1010).

In this regard, the present writers go on to hold that an absolutist perspective in language acquisition is implausible. Henceforth, it is suggested a multimethod approach: deductive-inductive-abductive method; in fact, language acquisition is not compatible with a unimethod approach; thus, claiming that the child acquires language predominantly through the process of either, deduction, induction, or abduction is illegitimate. As Gibson (1992) assert "just as there are pros and cons associated with hypothetico-deductionism, so there are pros and cons associated with analytic induction, another type of scientific method" (p. 15), and also for abductionism. In effect, as Gibson suggests, "there are things to be admired then both in the deductive strategy, and in the inductive strategy" (p. 17), and the abductive strategy is not an exception. But what is not tangible is as to why such little progress has been made to achieve symbiosis between the three positions. As Bulmer (1984, cited in Gibson, 1992) states, there appears to be no real theoretical reasons why certain facets of the positions should not be combined, while many researchers argue that this is absolutely necessary.

\section{References}

Agassi, J. (1997). The novelty of Chomsky's theories. In D. M. Johnson \& C. E. Enerling (Eds.), The future of the cognitive revolution (pp. 136-148). Oxford: Oxford University Press.

Baker, A. (2006). Occam's Razor in science: A case study from biogeography. Biology and Philosophy, 22, 193-215. http://dx.doi.org/10.1007/s10539-006-9027-9

Berthele, R. (2011). On abduction in receptive multilingualism. Evidence from cognate guessing tasks. Applied Linguistics Review, 191-220. http://dx.doi.org/10.1515/9783110239331.191

Birjandi, P., Shakouri, N., \& Mellati, M. (2012). An attempt toward a tentative complementary perspective in language acquisition: A panacea. World Applied Sciences Journal, 24(8), 1009-1015.

Bourke, J. M. (2005). The grammar we teach. Reflections on English Language Teaching, 4, 85-97.

Chaudron, C. (1988). Second language classrooms, research on teaching and learning. Cambridge: Cambridge University Press. http://dx.doi.org/10.1017/CBO9781139524469

Chomsky, N. (1957). Syntactic structures. Paris: Mouton.

Chomsky, N. (1965). Aspects of the theory of syntax. Cambridge: MIT Press.

Chomsky, N. (1981). Lectures on government and binding. Dordrecht: Foris.

Cook, V. J. (1988). Chomsky's universal grammar: An introduction. Oxford: Basil Blackwell.

Cook, V. J., \& Newson, M. (1996). Chomsky's universal grammar: An introduction ( ${ }^{\text {nd }}$ ed.). Cambridge: Blackwell. 
Abductionism: An attempt to achieve symbiosis

Duetscher, G. (2002). On the misuse of the notion of 'abduction' in linguistics. Journal of Linguistics, 38, 469-485.

Ellis, R. (1994). The study of second language acquisition. Oxford: Oxford University Press.

Gibson, T. R. (1992). Towards a discourse theory of abstracts and abstracting. Unpublished doctoral thesis, University of Nottingham.

Goodman, N. (1967). The epistemological argument. In N. Goodman (Ed.), Problems and projects (pp. 69-75). Cambridge: Harvard University Press.

Haig, B. D. (2005). An abductive theory of scientific method. Psychological methods, 10(4), 371-388. http://dx.doi.org/10.1037/1082-989X.10.4.371

Hanson, N. R. (1958). Patterns of discovery. London: Cambridge University Press.

Hornstein, N., \& Lightfoot, D. (1982). Introduction. Explanation in linguistics. The logical problem of language acquisition. London: Longman.

Hume, D. (1977). An enquiry concerning human understanding. Indianapolis: Eric Steinberg.

Jabbari, A. A., \& Niroomizadeh, A. K. (2005). The effect of negative and positive evidence on learning English as a foreign language by Persian speakers. Journal of Faculty of Letters and Humanities, 51(206), 45-61.

Jovanovic, A. S., \& Krneta, G. G. Z. (2012). Abductive reasoning and second language learning. Journal of Language Teaching and Research, 3(2), 306-313. http://dx.doi.org/10.4304/jltr.3.2.306-313

Kuhn T. (1970). The structure of scientific revolutions ( $2^{\text {nd }}$ ed.). Chicago: University of Chicago Press.

Lange, M. (2008). Hume and the problem of induction. In D. Gabbay, S. Hartmann, \& J. Woods (Eds.), Handbook of the history of logic (pp. 43-91). London: Elsevier BV.

Larsen-Freeman, D. (1997). Chaos/complexity science and second language acquisition. Applied Linguistics, 18(2), 141-165. http://dx.doi.org/10.1093/applin/18.2.141

Laurea, T. D. (1995). Language acquisition and universal grammar. Retrieved in May 1, 2012, from http://www.maldura.unipd.it/ddlcs/GeD/gentile

Laurence, S., \& Margolis, E. (2001). The poverty of stimulus argument. British Journal for the Philosophy of Science, 52, 217-276. http://dx.doi.org/10.1093/bjps/52.2.217

Long, M. H. (1993). Assessment strategies for second language acquisition theories. Applied Linguistics, 14(3), 225-249. http://dx.doi.org/10.1093/applin/14.3.225

Long, M. H. (1996). The role of the linguistic environment in second language acquisition. In W.C. Ritchie \& T. K. Bhatia (Eds.), Handbook of research on language acquisition (pp. 413-468). New York: Academic Press.

Mitchell, R., \& Myles, F. (2004). Second language learning theories (2 ${ }^{\text {nd }}$ ed.). New York: Oxford University Press.

Newport, E. L. (2011). The modularity issue in language acquisition: A rapproachement? Comments on Gallistel and Chomsky. Language learning and development, 7(4), 279-286.

http://dx.doi.org/10.1080/15475441.2011.605309

Peirce, C. S. (1998). The essential Peirce. In N. Houser, C. Kloesel, \& the Peirce Edition Project. Bloomington, IN: Indiana University Press.

Pinker, S. (2004). Clarifying the logical problem of language acquisition. Child Language, 31, 949-953. http://dx.doi.org/10.1017/S0305000904006439

Popper, K. (1976). The logic of scientific discovery. New York: Basic Books.

Putman, H. (1967). The innateness hypothesis and explanatory models in linguistics. Philosophical Papers, 2 , 107-116.

Schachter, J., \& Yip, V. (1990). Grammaticality judgments. Studies in Second Language Acquisition, 12(4), 379-392. http://dx.doi.org/10.1017/S0272263100009487

Shank, G. (1993). Abductive multiloguing: The semiotic dynamics of navigating the net. Retrieved May 1, 2013, from http://www.ibiblio.org/pub/academic/communications/papers/ejvc/SHANK.V1N1

Skinner, B. F. (1957). Verbal behavior. Englewood Cliffs, NJ: Prentice Hall. http://dx.doi.org/10.1037/11256-000 Sørensen, B., Thellefsen, T., \& Brier, S. (2012). Mind, matter, and evolution: An outline of C. S. Peirce's 
Maftoon, P., \& Shakouri, N.

evolutionary cosmogony. Cybernetics and Human Knowing, 19(2), 95-120.

Wilkin, P. (1999). Chomsky and Foucault on human nature and politics: An essential difference? Social Theory and Practice, 25(2), 177-210. http://dx.doi.org/10.5840/soctheorpract199925217

Wirth, U. (1998). What is abductive inference? Retrieved May 1, 2013, from

http://user.uni-frankfurt.de/\%7Ewirth/inferenc.htm 